\title{
Aristotelian Analysis of Parvin E'tesami's Poems: "The Reliever", "Two Courts" and "Words and Deeds"
}

\author{
Ahad Mehrvand \\ Assistant Prof. of Literary Studies, Department of English Language and Literature, \\ Azarbaijan Shahid Madani University, Tabriz, Iran \\ ahadmeh@yahoo.com
}

\begin{abstract}
Keywords: Peripeteia, Anagnorisis, Aristotle, Parvin E’tesami, "The Reliever", "Two Courts", "Words and Deeds"
\end{abstract}

\begin{abstract}
The present paper aims at proving that Parvin E'tesami has been, consciously or unconsciously, under the profound influence of both ancient Persian and Western literatures in composing her poems. The overseas effect is mainly due to her translations of Western works and her intimate familiarity with Western literature. So far research into Parvin's treatment of Aristotle, as founder of Western literary theories, has not yielded a promising result. The present researcher attempts to answer the question whether or not Aristotelian elements of anagnorisis and peripeteia play any roles in Parvin's poems, and if so, how she uses them in some of her poems. The findings of this research show that, in the three selected poems, namely "The Reliever," "Two Courts," and "Words and Deeds," Parvin has used the third type of anagnorisis and peripeteia, in which they happen concurrently, rather than the other two types, in which anagnorisis and peripeteia either precede or succeed each other. Parvin has not used these two Aristotelian concepts accidently. The use of the concurrent type becomes more significant if we know that it is the best type of Aristotelian usages of these two terms, an application which rightly and effectively paves the way for internal and external changes of the central character in the poems.
\end{abstract}

\section{Introduction}

Parvin E'tesami, whose given name was Rakhshandeh, was born on March 16, 1907, in Tabriz, East Azarbaijan province of Iran. Since her father Yusuf E'tesami was elected as an MP for Tabriz in the second Parliament, her family had to move to Tehran in 1914. She stayed there till the end of her life and eventually died of Typhoid fever in Tehran in 1941 but was buried next to her father in Qom. Her gravestone bears her famous literary epitaph:

Beneath this soil which verdure refuse,

Lies Parvin, literary star and muse;

Who,

While suffering the bitterness of Times,

Composed charming, sugar-laden rhymes.

Parvin is one of the most famous Twentieth-Century Iranian poets whose fame is comparable to other poets and authors prior to her, namely Rumi, Nasser Khosrow, Sa'adi, and Ferdowsi, whose works she had read and been heavily influenced by [1]. From her father, Yusuf (E'tesam al-Mulk), she obtained her knowledge of Arabic and Persian literatures. She started composing poems at the age of eight. It was in 1920 when her father founded a literary journal named Bahar, in which Parvin published regularly and established her literary talent in a maledominated society. However, her father had the idea that her progress was not adequate although she had been under his personal instruction and also received instruction from capable instructors of public and private schools in Tehran. He thought they did not incorporate modern techniques and views. Therefore, he had Parvin attended the American College for Girls, where she was exposed to the English language. Hence, what makes Parvin different from other Persian poets is being 
educated and even teaching for a while at an American high school for girls, called the Iran Bethel School, founded by American missionaries in Tehran in 1874. This experience led to Parvin's inescapable familiarity with solid Western cultures, thoughts, and literature. Parvin and her father traveled to Europe. According to I. Bashiri, these journeys acquainted Parvin with "the cultures and traditions of the peoples of the West. In later times it was on this knowledge that Parvin drew for themes for her poems." Bashiri specifies the effect of the 1930's literary gatherings on Parvin, in which not only did she hear discussions (between Malak al-Shu'ara Bahar, Shahriyar, and her father) on Iranian life and culture as well as people's sufferings, but also "Parvin, reportedly, participated in these meetings and contributed to them by reciting her poetry." Due to the vast amount of her knowledge, Parvin was asked to tutor the queen of Iran in 1926, and a decade later, was offered a medal for her contribution to Persian literature by the Ministry of Culture. She declined both; the former due to her criticism of Reza Shah's policies and the latter for the motivation behind the medal, which served offerers' exploitive interests and which lacked, as Parvin claimed, "a genuine appreciation of her poetry" [2].

This article is based on a Persian paper initially aimed at Iranian audience (Mehrvand and Khamne). In the present paper, in addition to discussing the effect of Western literature on Parvin in general and Aristotle in particular, the researcher, using Aristotle's theories on tragedy in Poetics, intends to examine the role of anagnorisis and peripeteia in three of Parvin's poems, namely "The Reliever," "Two Courts," and "Words and Deeds." Parvin, as one of the greatest Iranian poets, is mainly known for the depiction of social problems in her poetry, however, one of the most important aspects of her poetry is the amalgamation of classical poetry with modern one and its being under the influence of Western literature. Nevertheless, no research so far has directly explored the influence of Aristotle on Parvin. The present research attempts to answer the question whether or not we can find the Aristotelian elements of anagnorisis and peripeteia in Parvin's poems, and if so, how she uses them in some of her poems.

\section{The Influence of Western Literature on Parvin's Father and Her own Works}

Throughout her literary career, Parvin wrote 42 odes, 167 lyrics, parables, allegories and other poems. In 1935, she published her Collection of Poetry. According to M. Rohani, by 1935, "she was a renowned poet who had been writing poetry for 20 years" [3]. In a preface to the translation of Parvin E'tesami's Collection of Poems into English in 2002, A. Pazargadi clarified that Parvin was "a follower [of Nasser Khosrow] in the choice of diction, subject matters, simplicity of form and composition. However, her short poems show a greater variety of form and are more modern in style" [4]. According to M. Ishagh, the Indian author and the instructor of Persian literature, "Parvin is a modern poetess due to the choice of subject matter and the style of composition and it is easy to trace the effect of Western education in her poetry" [5]. That Parvin was a capable poetess and that her reliance on her studies and on her sustained effort made her an established poetess among great Iranian poets is beyond doubt. However, a cursory look at her father's life and works shows that Parvin has learned a lot from her father and has used them in her poetry since her father's training familiarized her not only with traditions of Persian literature but also "with European literatures." Rohani stated that Yusuf E'tesa-Molmolk had a high command of French and Arabic, which made him have "access to books and journals published in Cairo, Damascus, Baghdad, the Caucasus, and Europe." Pazargadi disclosed two of Yusuf's contributions, namely founding a journal and translating a book into Persian: "For many years he acted as a chief librarian in Iran's parliament library. His written works include two rounds of the Journal Bahar, most contents of which were his own works; and he translated Victor Hugo's 'Les Miseables' into Persian." Bahar, a sixty-four-page monthly published in 1910-1 and 1921-2, was profoundly influenced by the dominant Western thought of the Mashrooteh era, that is, Iranian Constitutional Revolution. E. G. Browne, who authored A Literary History of Persia, found Bahar "very modern and European in tone" [6]. 
In an article entitled "Getting to Know the Bahar Magazine," A. Athna-Ashari disclosed that, like most journals of that era, Bahar was dominated by Western culture, especially the French, since its authors were those who had been either to Europe or educated from modern European-syle schools in Iran [7]. Similarly, V. Doroodian verified the effect of the West on Bahar essays, stating, "Most of the essays published in Bahar were translations from the Western, Turkish and Arabic poets and authors. Bahar is one of the credible monthly journals that played an important role in introducing Iranians with the Western authors, poets and intellectuals" [8].

Some of major characteristics of Persian literature in the Mashrooteh era, as discussed by M. Mosharraf, are as follows: "Freedom, equality for men and women, modernism, anti- superstition, culture and modern education, and praising modern science" [9]. A cursory glance at Yusuf E'tesami's works shows that themes of his works include the aforementioned characteristics. For instance, the Persian book entitled Tarbiat-E-Nesvan (Women's Eduction) is a translation of the Egyptian author G. Amin's book entitled Tahrir al Mara'a (The Liberation of Women). This book depicted, among other things, the equality of men and women. In his book entitled Az Nima ta Roozegar-e Ma (From Nima till Our Era), Y. Arian-pour claimed that Yusuf E'tesami could be the founder of Feminist literature in Iran [10]. Such a view is supported by Mosharraf, who asserts,

In various issues of Bahar, there are many essays about education of women as a central subject. In these issues, there are news of American and European inventions and developments made by women, the women's attempts to join the parliaments in Europe, and their participation in general services and governmental offices, and the feminists' demonstrations in London.

Some of Parvin's poems deal with women's rights - poems such as "Women in Iran," "Nahal-e Arezou ("Seeds of Hope"), and "Fereshtey-e Ons," addressing injustice against and restrictions on Iranian women. Thus, it can be noticed that Parvin inherited her concerns over women's issues from her father. Beginning with the Mashrooteh era, poetry, as M. Hoghughi asserts in A Survey of History of Literature and Iran's Contemporary Literature, "varied only in concepts and themes" but "in the form it had no differences with the poems composed in the past" [11]. In other words, Parvin's poetry follows the classical Persian tradition in its form but its content is modern. Therefore, as in an article entitled "Parvin E'tesami at the Pathway of Tradition and Modernity," M. Mohseni and G. Pirouz postulate, "Parvin's poetry is a fusion of traditional and modern literature" [12]. One of the reasons why the form of poetry remained constant in the Mashrooteh era, according to M. S. Kadkani, was due to the "publication of books, grammatical discussions and controlling literary societies" of the time's government, which attempted to preserve and promote traditional literature [13]. However, both M. E. Nodushan and Y. Azhand deny it, trying to prove that, among their various discussions, it was the translation of Western poets that affected Iranian poets. The impact of European poetry on contents of Persian poetry in the Mashrooteh era, as Nodushan explicitly explicates, "is undeniable and individual translations from poets such as La Fontaine, Victor Hugo and Lamartine had influenced our speakers" [14]. Mosharraf asserts that "due to his translation of Victor Hugo's Les Misérables and some other prose passages into Persian, Yusuf E'tesami made Iranians familiar with the thought of the Romantic era." In one of issues of Bahar, as Kadkani claims, Yusuf defended the idea of being familiarized with Western literature and "noted the necessity of obtaining permission for foreign literature" [15]. Apart from Parvin's total awareness of English literature, she has "undoubtedly been influenced by European thought, especially from her father E'tesamolmolk's translations from French speakers" [16]. According to Azhand, "Parvin's poetry is amalgamation of the wisdom and ancient advice along with a kind of compassion and reaction to domestic issues that are indicative of the ancient writers and often encapsulates Romanticism that is affected by the Western Literature." 
Some of Parvin's poems are translations from published Western poems such as "Arzeshe Ghowhar" ("Value of Jewel") from the French poet Jean de La Fontaine; "Paaymale Az" from Aesop; "July Khoda" by the American writer A. Brisbane; "Naghme Roofoogar" by the English poet Thomas Hood; "Yade Yaran" from "Be yek Moomyaee Mesr" ("Address to the Mummy in Belzoni's Exhibition") by the English poet H. Smith; "Ashiyane Viran," a poem "constructed under the influence of the Western Romantic poets"; and "Gatarate Se Ganeh" by the Italian poet Trillo. This has been the origin of an inspiration for one of Parvin's masterpieces [17].

A careful reading of Parvin's poems reveals subtle signs of Western literature, alongside which she preserves "Eastern and moral originalities" in order to deepen her poems and adapt them to requirements of her own time [18]. According to A. K. Hakkak, "there is the underlying stream flow contrary to the apparent course of tradition in Parvin's poetry and several other Persian poets in the early Twentieth-Century movement, therefore it is not visible to the eyes of a quick and hasty looker" [19].

Indeed, the influence of Western literature on Parvin is not limited to translation and themes of her poetry and, as this paper intends to show. Parvin might have benefited from Aristotle's literary theories to compose her narrative poems. The remarkable thing is that terms introduced in Aristotle's Poetics are universal and can be seen in almost all narrative works. Although the ubiquity of Aristotelian terms in the internal plot of Parvin's narrative poems may imply that Parvin was influenced by Western literature, no research so far has highlighted the direct or indirect impact of Aristotle, the first literary theorist of the West, on Parvin's poems.

The present research does not aim to offer a general analysis of all poems in Parvin's Collection of Poems or to use all Aristotelian terms discussed in Poetics. It only limits itself to showing how the most important terms, namely angnorisis and peripeteia, discussed in the plot of narrative poems, can play a significant role in understanding three of Parvin's best poems, namely "The Reliever," "Two Courts," and "Words and Deeds." These poems have been taken from A. Pazargadi's translation of Parvin's Persian Divan into A Collection of Parvin E'tesami's Poems (2002). All references to the mentioned poems in the present paper have been taken from Pazargadi's work. Below the researcher intends to define the Aristotelian terms and then apply them to Parvin's selected poems.

\section{Anagnorisis and Peripeteia}

Anagnorisis and peripeteia are two important components of tragedy. Aristotle discussed them for the first time in his Poetics. Anagnorisis and peripeteia in English are the translation of the

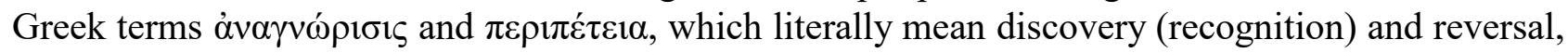
respectively. In Chapter 11 of Poetics of Aristotle edited by S. H. Butcher, Aristotle defines anagnorisis as a change from ignorance into knowledge, leading to either friendship or enmity. For instance, at the end of the play Oedipus Rex, it is Oedipus who eventually finds out in consternation that the man he killed and the woman he married were his true parents. In Chapter 10, Aristotle divides plots of tragedy into simple and complex ones. By a simple plot, Aristotle means a plot in which "the change of fortune takes place without Reversal of the Situation and without Recognition." By contrast, a complex plot/action is the one "in which the change is accompanied by such Reversal, or by Recognition, or by both" [20]. Aristotle stresses that recognition and reversal ought to be used on the basis of the internal structure of the plot in such a way that what follows after these literary elements should be the result of what happens out of necessity or probability.

Turning to peripeteia/reversal, Aristotle elucidates that "Reversal of the Situation is a change by which the action veers round to its opposite." For instance, toward the end of Sophocles's play, Oedipus undergoes a change, turning from a prince to a blind pauper who experiences the exile, as his oath demands, after discovering that he has committed both patricide and incest and that it is the cause of pestilence in Thebes. Similar to anagnorisis, peripeteia is subject to Aristotle's internal rule of probability and necessity. Another example about peripeteia is again from Sophocles's Oedipus 
Rex, in which the messenger enters to liberate Oedipus from his mother's anxieties but, just the contrary, the story ends up revealing who Oedipus truly was: a man who has inadvertently had an incestuous affair with his own mother.

According to Aristotle, the main purpose of using anagnorisis and peripeteia is to "turn up surprises." Besides, these two elements produce the main effects of tragedy, namely pity or fear. "This Recognition combined with Reversal," according to Aristotle, "will produce either pity or fear; and actions producing these effects are those which, by our definition, Tragedy represents."

Concerning the order and timing of these Aristotelian elements, Aristotle does not mention how many situations we can find for the terms anagnorisis and peripeteia in a complex plot. He merely says what situation is the best one that a good poet can use: "The best form of recognition is coincident with a Reversal of the Situation, as in the Oedipus." In Chapter 16, however, Aristotle explains six kinds of anagnorisis from the least to the most important ones: recognition by signs, recognition invented by the poet's art, recognition made through a memory when the sight of an object evokes a feeling, recognition through a process of reasoning, false recognition due to a false interpretation of the truth, and recognition arising from incidents themselves, which is made naturally in the course of the plot. He regards the sixth one as the finest due to its naturalness:

But, of all recognitions, the best is that which arises from the incidents themselves, where the startling discovery is made by natural means. Such is that in the Oedipus of Sophocles, and in the Iphigenia; for it was natural that Iphigenia should wish to dispatch a letter. These recognitions alone dispense with the artificial aid of tokens or amulets. Next come recognitions by process of reasoning.

Thus, Oedipus Rex is one of the best Greek plays because, in this play, not only is anagnorisis concurrent with peripeteia, and the sixth type of anagnorisis has been effectively used, but also it is the best natural type obtained from the process of reasoning. Therefore, the events at the end of the play occur in a way that, immediately after realizing the true identity of his parents, Oedipus's and his mother's fortunes change drastically. His mother commits suicide and Oedipus ends up as an exiled blind beggar who departs Thebes.

Using lots of Greek terms/sentences employed in Poetics, in an article entitled "Aristotle's Definition of Anagnorisis," J. Macfarlane delineates misconceptions revolving around the term anagnorisis by arguing against some of G. F. Else's translation of passages on anagnorisis in Aristotle's Poetics: The Argument. Macfarlane clarifies that the Greek term $\mu \varepsilon \tau \alpha ß o \lambda \eta$ stands for "both a recognition and a reversal: this is the kind of recognition Aristotle calls "finest" [22]. However, the term $\mu \varepsilon \tau \alpha ß o \lambda \alpha i$ refers to other kinds of recognition without reversal. Despite the fact that Macfarlane belives both terms can be used simultaneously or separately, he does not mention the situations/types in which anangnorisis and peripeteia can be employed by poets.

Nonetheless, the author of this paper in a joint Persian paper with A. A. Khamne classified three situations/types for these two Aristotelian terms: the first type is the one in which anagnorisis is preceded by peripeteia. It is the time when Tiresias asserts that Oedipus is the murderer of the previous king. In fact, Tiresias helps Oedipus achieve an early anagnorisis prior to his eventual peripeteia but Oedipus's tragic flaws interrupt the occurrence of these two Aristotelian concepts; the second one is the one in which anagnorisis follows peripeteia. This happens after Jocasta's suicide as her peripeteia. In fact, after hanging his mother, Oedipus discovers what peripeteia has happened to his mother; and the third type is the one in which anagnorisis and peripeteia occur concurrently, which is the one Aristotle stressed in Poetics. Aristotle limits himself to mentioning the best type of anagnorisis, which is immediately followed by peripeteia or is natural. Similar to Macfarlane, Aristotle ceases to explicate the order in which situations/types of anagnorisis or peripeteia occur. Neither do they distinguish between anagnorisis and peripeteia in terms of commonalities and differences. However, in the Persian paper, the researcher of this article and Khamne have further clarified how anagnorisis and peripeteia are similar to or different from each other in order to resolve the misconceptions around these terms: 
An important point that should be remembered, is the similarity and difference between discovery [anagnorisis] and reversal [peripeteia]. Both of these elements refer to changes in personality and in this respect they resemble. The difference is that discovery [about a person or a thing] is an internal, invisible and intellectual change [in the character and the audience] that transfers the character [and the audience] from ignorance to knowledge. However, reversal is an external and visible change in the character's fortune [, thought, action, health and profession] that is observable such as a fall from the peak to a valley, or as a pauper who becomes a prince [or vice versa], or a person who is struck with fortune [or misfortune/catastrophe] [23].

Drawing upon the character of Oedipus, in an article entitled "The Problem of Dramatic Expectation in Aristotle's Poetics," and providing a detailed explanation of Greek terms and quotations, C. D. Corcoran asserts that Oedipus's understanding of his deep ignorance of his origin shows ignorance about human condition, which means both the hero and the audience undergo such an anagnorisis. Thus Corcoran connects, among other issues, anagnorisis in the character/hero to anagnorisis and catharsis in the audience:

[W] hat is recognition on the part of a tragic character is often the catalyst for catharsis in the audience. ... A condition for the occurrence of catharsis is the intersection of the audience's recognition with that of the hero's discovery. His recognition is now their pity for what they had feared all along. When their knowledge is identical with the hero's, the tension of the audience's knowing something the hero does not know is relieved, and their pity and fear are then purged [24].

Corcoran concludes his article with the surprising roles of anagnorisis and peripeteia that may result in anti-expectation effects on the hero: "In conclusion, the poet may choose a course of action contrary to opinions that are generally held $(\dot{\varepsilon} v \delta o \xi \alpha)$ in order to demonstrate the error they involve (hamartema or hamartia)."

Both peripeteia and anagnorisis are the most powerful parts of a plot in a tragedy or other works. Aristotle's literary theory is restricted to poetry, especially tragedy. He did not formulate a theory on comedy. In recent studies, the two Aristotelian elements of anagnorisis and peripeteia have been studied in comedy because both tragedy and comedy have plots and the discovery and reversal can bring tears or laughter to the audience, respectively [25]. Apart from comedy, we can even find anagnorisis and peripeteia in the plot of short stories. For instance, B. Meghdadi's book entitled Dictionary of Literary Theory Terms: From Plato to the Contemporary Age has devoted four pages to the role of anagnorisis in detective stories, particularly in Edgar Alan Poe's "The Purloined Letter" [25]. Thus, due to the centrality of the plot in tragedy, comedy, and short as well as long stories, it is probable to find the two Aristotelian elements of anagnorisis and peripeteia in narrative poems as well. However, the question put here is whether Parvin's best narrative poems have ever used these Aristotelian terms or not. In the following section, the researcher intends to examine anagnorisis and peripeteia in "The Reliever," "Two Courts," and "Words and Deeds" to highlight their significance in Parvin's poems.

\section{4. "The Reliever"}

As one of Parvin's best poems, "The Reliever" is a poem called Masnavi in Persian, which is very similar to the English heroic couplet in rhyming. It is the story of a destitute old man whose children were ill and needed food (honey and soup) but the old man could not afford to provide food for them. Finally, after some fruitless efforts, a miller granted the old man a bag of wheat. He shouldered the bag and headed home but since the wheat alone was not sufficient to solve his problems, he, on the way, prayed to Allah for granting his daily bread and solving his problems: 
"Great God, If you / give me a hand with Your benevolence, the knot / of times will be untied for me" (30-32).

After his fervent prayers, the man realized that it had been for a while that the knot of the bag had been undone and the wheat had spilled onto the ground. Therefore, in dismay at the weakness of God in distinguishing the knot of the wheat bag from the metaphorical knot of his problems, the old man voiced his sullen complaints through the following soliloquy: "O Just God, with all Your wisdom, didn't You / know?" "And despite long years of Your Godship, that this / is not the knot I asked You to untie?" (47-50).

Despite disappointment, the old man got busy gathering grains of the wheat from the ground, and much to his surprise, he found a bag of gold in the grains. It was at this moment that he underwent both anagnorisis and peripeteia: the old man, who had been disappointed with God's grace and who had doubted His divine knowledge, discovered his mistake after discovering the bag of gold and noticed God's greatness, concluding that "If anyone receives a pain / from You, it is You who are eventually his / doctor" (81-82).

In the poem, anagnorisis stands for an internal, intellectual, and mystical change in the old man's understanding of God's grace and providence whereas preperteia establishes a visible and external change in the old man's fortune to such a degree that he can afford not only the cost of medicine and food but also the future cost of living for some time. Hence, the old man's visible change (peripeteia) is from destitution to affluence. Parvin uses soliloquay in the poetry to make the reader discover the inner change in the old man's knowledge. In fact, in this poem, anagnorisis happens to the old man twice. The first one was after the bag was untied, the wheat spilled onto the ground, and the old man jumped to a hasty discovery, conclusding that God was unable to distinguish a literal knot from a metaphorical one. The latter anagnorisis took place when the old man found the bag of gold. The difference lies in the fact that the former occurred singly and separatelybut the latter occurred simultaneously with peripeteia. Since the second situation employs two kinds of change in the character and the reader alike in a surprisingly unexpected way, it can be said that it is the best type based on the Aristotelian defintion. Another difference between the two anangnorises of the old man is related to the types of these recognitions. The former can fall within the fifth type of Aristotle's anagnorisis, which is based on a false interpretation. But the second anagnorisis is comparable with Aristotle's sixth type of anangnorisis, which is natural and arises from the internal incidents of the poem's plot. Since Aristotle calls the sixth type of anagnorisis as the best one, Parvin's use of this particular type of anagnorisis makes it effective. Besides, for Aristotle, the finest anagnorisis is the one that is simultaneous with periperteia. Since the second one in this poem is also accompanied by peripeteia, the researcher claims that the reason why "The Reliever" has been considered to be among the best poems of Parvin is due to such a natural reasoning, due to the use of the sixth type of anangnorisis, and due to its simultenous occurrence with periperteia.

The second soliloquay of the old man starts immediately after finding the bag. It adresses not only the old man and the reader but also Parvin herself and stresses the existence of ignorance in in the human's nature and underscores the significance of trusting in divine Providence.

"Whoever is impoverished and distressed for Your sake, is wholly unaware that he is Your guest." "The ignoble did not give me any food, to make me realize that You are the asylum of the friendless."

"You make a healthy creature feeble, so that he realizes that all he has is due to You." "You have sent me poor dervish to every door, so that I may recognize my God." "You lowered me down into an abyss, so that I may seek You and call You exalted." "I turned to the people on the day of 
need, though it was Your door that was always open." "I have come across many men of wealth, but You are the most generous, O Almighty God!"

"When I dropped helpless at the door of the base, it was You, O God, Who held my hand."

"You spilt my wheat in order to grant me gold;

You cut the string so as to give me pearl." O Parvin, it

is you who may lack thought and intellect, otherwise

the pot of God is eternally boiling (83-101).

According to A. Hajian-Nezhad's article entitled "Parvin's Storytelling in Her Masnavis," Parvin's method of narrating the couplets ends up with

saying the providence behind God's affairs, stressing that God's work is totally different from that of His creatures in that He always considers the prudence and expediency... however, it is due to our limited, intellectual and emotional capacity that the subordinates like us do not understand our expedience and quickly jump into conclusions.... whereas, what is in our vantage point as incorrect and sulky, in fact, in His graceful view is for our true expedience and goodness [27].

\section{5. "Two Courts"}

Similar to "The Reliever," the poem "Two Courts" is a Masnavi of complaint; the difference is that it is not allegorical. Some critics found "Two Courts" among Parvin's feminist poems. For instance, according to G. Sadeghi and B. Parhiz-gari, "The poet in this poem has attributed the hidden image of meaningful and life-giving women to men who assume themselves to be of legitimate authority" [28]. The Persian word "mahzar" is translated into the titular word "court" in English. This word in Persian is a pun carrying two meanings: one refers to the court of justice in which people's disputes are handled and the other stands for the house. Thus, in this poem, the court and the house have been compared.

"Two Courts" is a poem about the judge of Keshmir who once entered the house in a very angry mood, blaming everybody, especially his wife, for laziness because he believed that she was indifferent to problems in men's lives and spent her days at home in a carefree way. The man grumbled sullenly, wishing to change his dwelling from the court to the house. Contrary to the judge's expectations, his wife accepted the offer and left the house and asked the judge to run home affairs to for a few days. In the beginning, everything went on well as usual but, after a few days, chaos broke out at home. The servant, the chef, and the footman kept exchanging stones, fists, and sticks against the doorkeeper and revealed each other's flaws, negligence, and secrets. Everyone accused the others of theft and robbery in the kitchen and at home, trying to plead innocence to any sin the judge knew. Meanwhile, the gardener came forth and revealed what the steward had done apart from stealing gold: "Last night he wrote down three kilos as one ton, / and stated a few pounds of wheat as several thousands." The maid claimed that the children stole the tablecloth after eating all the bread and honey. After all, the perplexed judge failed to resolve the dispute between them. Thus, he recognized his mistake and decided to leave the house for the courtroom. This was when the anagnorisis and peripeteia happened simultaneously to the judge. At first, the judge thought that he worked harder than women in the house and that was why he blamed his wife for laziness. However, after a little argument between the members of the house, he noticed that he could not settle even a single dispute at home. Therefore, he started confessing and expressing remorse for his mistake, deciding to return to the court.

The judge realized that the house is full of riot and confusion, looking like a court but a riotous court

His task as a judge had been confined to pen and paper, 
and he was not familiar with this new court.

How could he know where the riot had its root, or who had caused all that addition and diminution?

As he could not distinguish the honest from dishonest

he took up his files and records under his arms.

Saying: "All these disputes have given me a headache,

I must go back to my court, as it is getting late" (111-120).

Before the judge's departure, his wife arrived, and now it was her turn to blame the judge. As a wise woman, she revealed the reason why he could not play the role of a successful judge at home: the accused in the court were scared of the law and its punishment; however, they were not frightened of him anymore at home. The internal and external changes that happened to the judge are remarkable. After the judge realized that he was not able to settle domestic disputes, he noticed the major difference between the court in the house and the court of justice, despite so many similarities. In both, the purpose was resolving the disputes; however, the judge was not able to avert chaos at home, being merely successful in judgement outside the home. Thus, his vantage point changed along with the internal change in his character, which rendered him more respectful of his wife's management and her daily attempts to establish order and security at home. The external change that happened concurrently with the internal one was represented in his departing of the house for the court of justice because the judge had been defeated in this battle and was remorseful. Nevertheless, this change remained more evident when he became silent before his wife's final reprimand.

\section{6. "Words and Deeds"}

Words and deeds" is an allegorical poem in the form of an ode. The use of animals in this poem sets it among parables. In beast fables, animals are used as a symbol for introducing didactic concepts. For example, a parrot may be a symbol of a negligent man whereas an ant may stand for a hard-working person. These kinds of fables always end with a moral [29]. Beast fables were introduced to Iran by N. Monshi's translation of Kalileh and Demneh from Arabic into Persian in the sixth century. In fact, the purpose of such stories, which are also called mysterious allegory, is to express "moral and doctrinal meanings and teachings." The presence of animals in the story indicates

mixing human and animal worlds ... which has been considered in mystical or mysterious texts, and poets like Parvin have been clever to benefit from this didactical method, and through using an indirect method like her predecessors she has expressed moral and human teaching in the form of anecdotes under the pretense of attractive, mysterious, and allegorical language in the form of dialogues among animals [30].

The poem "Words and Deeds" begins with a lion's fierce admonish of a cat. The lion calls the cat a self-indulgent, mean animal that does not go hunting and just resorts to snatching everybody's food. From the lion's point of view, the old woman, the peasant, the poor, and the rich are never safe from the cat's robbery. As a result, he gains without pains the product of others' labor and does not care whose food it is. The lion continues reprimanding the cat, commanding him not to blacken his head, ear, and tail by attacking cooking pots, which represents his black heart.

The lion proposes that the cat go to the thicket/wood and become a free animal because the lion believes that conscientious, free animals hunt sleeping preys provided that their teeth and claws be sharp. The lion further speaks about advantages and disadvantages of life in the woods and cities, respectively. The cat, therefore, accepts the lion's advice to seek a more dignified and fruitful life in the woods. The cat goes to a dark cave in the woods and roars like a lion, hitting the ground with his tail and testing how his ears are wriggling like a lion. Initially, the cat becomes so proud that he finds itself similar to the lion and discovers his hidden power. However, as the night falls and the 
moon rises, the cat gets frightened and hides in the corner of the cave. Ironically, at the same time, smelling the prey, a tiger comes toward the cave and waits in ambush at the mouth of the cave. The frightened cat hears his footsteps and runs toward the mouth of the cave. The cat regrets what he has done and misses the happy life he had had in the city.

In its last attempt to escape from the horror, the perplexed cat tries to run away but suddenly the tiger leaps out of the ambush, hitting his thighs and making him bleed. It is under the clutches of the tiger that the cat admits to his mistake:

"This is how foolish ones meet their death."

"I was a cat in the city, and became a lion in the mountain,

but I lost my life for the sake of vain fancy."

"This is the result of my selfishness and greed;

for, a heavy rain demolishes a weak building."

"Even if I resemble a lion in appearance,

I lack that strong heart, and that is enough deficiency (81-87).

Like the other two poems by Parvin, in this poem, the cat eventually undergoes a true anagnorisis and peripeteia simultaneously. Initially, due to the lion's imposed false anagnorisis, the cat found himself extremely powerful but, with the arrival of the night in the woods, he notices his mistake, concluding that living in the woods for a tame cat is very difficult and almost impossible (anagnorisis). Immediately after this inner change, the cat decides to escape but is captured in the grip of the tiger and loses his own life (peripeteia). The poem aims to give the didactic lesson that greed does not have a good outcome and everyone should expect progress based on their true power. Obviously, this self-knowledge is required to use the power of reason.

\section{Conclusion}

Literature has always been inextricably linked with other aspects of human life, and has been inspired by the historical, political, and social changes over the ages. To maintain its dynamism, literature may share didactic messages in pleasurable and indirect ways to meet its audience's expectations. By exploring the historical period in which Parvin lived, this article attempted to prove that Parvin's poetry had been influenced by Western literature consciously or unconsciously, along with ancient Persian literature. In the meantime, literary theories of Aristotle, the founder of literary theories in the West, were examined in the poems "The Reliever," "Two Courts," and "Words and Deeds." This study showed that these poems had used the simultaneous type of anagnorisis and peripeteia, as well as the natural, true type of anagnorisis (following a false anagnorisis), regarded as the best kind, according to Aristotle. The concurrent use of the Aristotelian elements of anagnorisis and peripeteia seems to have been intentional in Parvin's poetry because she helped both the character and the reader (modern and traditional) experience internal changes. However, apart from internal changes, the main characters of the poems experienced peripeteia as well. The effective use of these literary elements in Parvin E'tesami's narrative poems could make readers think deeply and understand each other and the world better.

\section{Acknowledgements}

The author would like to sincerely acknowledge a team of reviewers, including in alphabetical order, Dr. H. Baggali, Ms. S. Emami, Mr. N. Keramatfar, Dr. M. T. Khiabani, Mr. J. Khorsandi, Mr. A. Pourhasan, Dr. M. Pourya, Mr. M.Saadi-e Khosrowshahi, and Mr. A. Soleimani, for their comments on the present article. For the original research in Persian the researcher owes a big thank you to Mr. A. A. Khamene who helped publish the paper in a Persian journal. My special thanks go to Mr. M. Aghamohammadi for his great assistance in final proof reading this article. 


\section{References}

[1] M. Baghayee, Parvin E'tesami and the influence of early masters of Persian literature, Monthly Book reviews: Literature and Philosophy. 112-114 (2007) 36.

[2] I. Bashiri, A brief note on P. E'tesami's life, Retrieved from http://en.rafed.net/women-worldmainmenu/immortal-women/famous-women/840-a-brief-note-on-parvin-E'tesamis-life.

[3] M. Rohani, P. E'tesami: A Literary Star, The Iran Daily, Retrieved from www.irandaily.com/1391/1/14/MainPaper/.../MainPaper_4198_6.pdf.

[4] A. Pazargadi, A collection of P. E'tesami's poems, in: Alladin Pazargadi (Ed.), Translator's Preface, Tehran, Rahnema, 2002.

[5] M. Mosharraf, The concept of modernity and the neoclassical approach in P. E'tesami's divan, Didactic Literature Review. 11 (2012) 137.

[6] E.G. Browne, Literary history of Persia, Cambridge, The University press, 1928.

[7] A. Athna-Ashari, Getting to know the bahar magazine, Monthly Book reviews: Literature and Philosophy. 49 (2002) 127.

[8] V. Doroodian, A glance through Parvin's poetry and life, Monthly Book reviews: Literature and Philosophy. 112-114 (2007) 93.

[9] M. Mosharraf, P. E'tesami, the founder of neoclassical approach in Iran, Tehran, Sokhan, 2013.

[10] Y. Arian-pour, From Nima till our era, Tehran, Zavvar, 2003.

[11] M. Hoghughi, A survey of history of literature and Iran's contemporary literature, Tehran, Ghatreh, 2005.

[12] M. Mohseni, G. Pirouz, P. E'tesami at the pathway of tradition and modernity, Journal of Literary Studies. 7-9 (2006) 52.

[13] M.S. Kadkani, Cycles of Iranian poetry, Tehran, Sokhan, 2001.

[14] M.E. Nodushan, The crystal ball, Tehran, Golshan, 1996.

[15] M.S. Kadkani, With the mirror and the lamp, Tehran, Sokhan, 2013.

[16] R.I. Tabrizi, Character and ethics in fables of P. E'tesami and Jean de La Fontaine, Journal of Faculty of Literature and Humanoities of Tabriz University. 142-143 (1992) 5.

[17] Y. Azhand, Modern Literature of Iran. Tehran: Amir Kabir, 1984.

[18] A. Zarrin-Koob, With the caravan of holle, Tehran, Elmi, 2000.

[19] H. Khalegi-Rad, Parvin and her pieces, Quarterly Journal of Humanities of Alzahra University. 3-4 (1990) 21-22.

[20] A.K. Hakkak, P. E'tesami, An innovative poet: An analysis of the poem 'Julaye Khoda,' Journal of Iranain Studies. 2 (1989) 266.

[21] S.H. Butcher and Aristotle, Poetics of Aristotle, London, Macmillan, 1922.

[22] J. MacFarlane, Aristotle's definition of anagnorisis, American Journal of Philology. 121(3) (2000) 367-383.

[23] A. Mehrvand, A. A. Khamne, A study of Aristotle's discovery and reversal in three poems by P. E’tesami, Research in Contemporary World Literature. 19(1) (2015) 169.

[24] C.D. Corcoran, The problem of dramatic expectation in Aristote's poetic, Greek, Roman and Byzantine Studies. 38(3) (1997) 292-293. 
[25] L. Pandit, Emotion, perception and anagnorisis in the comedy of errors: A cognitive perspective, College Literature. 33(1) (2006) 94-126.

[26] B. Meghdadi, Dictionary of literary theory terms: From Plato to the contemporary age, Tehran, Fekr-e Rooz, 2000, pp. 394-399.

[27] A. Hajian-Nezhad, Parvin's storytelling in her Masnavis in collections of essays of the congress for glorifying P. E'tesami's 100th birthday. Ed. M. Akbari,Tehran, House of Books, 2008, pp. 102-103.

[28] G. Sadeghi, B. Parhiz-gari, Expression of traditional and modern components of woman in P. E’tesami's poetry, Research in Persian Language \& Literature. 20 (2012) 221.

[29] M.H. Abrams, G.G. Harpham, A glossary of literary terms. 9th ed. Boston, MA, Wadsworth CENGAGE Learning, 2009.

[30] H. Zommorodi, Analysis of history of beast fables and parables. in Collections of essays of the congress for glorifying P. E’tesami's 100th birthday. Ed. M. Akbari, Tehran, Khaneye Ketab, 2008 . 